\title{
EM BUSCA DO PLURALISMO JURÍDICO GLOBAL¹
}

\author{
IN THE QUEST OF GLOBAL LEGAL PLURALISM
}

\section{Mikhail Antonov}

Associate professor at the Law Faculty at the National Research University "Higher School of Economics" in Saint Petersburg (Russia).

\section{Resumo}

Globalização não é um termo descritivo para retratar a realidade contemporânea do direito; ela funciona principalmente como uma concepção regulatória para reforçar certas regularidades da evolução social para que sejam respeitadas por estudiosos, juristas e políticos. Os reflexos jurídicos em tempos de globalização não representam o direito como é, mas descrevem o direito necessário para que a humanidade encontre os perigos dos tempos de transição. Rejeitando por unanimidade o modelo Hobbesiano, os pluralistas apresentam as sociedades humanas como entidades auto-organizadas capazes de produzir suas próprias normas autônomas, independentes da vontade e da discricionariedade dos indivíduos particulares. Os fenômenos resumidos sob o título de pluralismo jurídico não têm originalidade histórica ou social. Pluralismo jurídico não revela novos direitos sociais ou regularidades, não provê um esquema explicativo novo (em vez disso, apenas muda as palavras do esquema antigo), e os desafios da globalização são apenas relativamente novos. Ao menos a realidade referida a esses termos esboça um clima intelectual renovado que oferece novos eixos aos discursos. Desse ponto de vista, o problema do pluralismo jurídico e a questão da globalização, não são desprovidos de interesse científico, e discussões sobre o tema podem efetivamente contribuir para o progresso do conhecimento social. Mas, de todas as possibilidades, não é razoável esperar que da substituição dos termos e dados factuais, se possa obter um conhecimento inovador sobre a interrelação entre direito e sociedade.

Palavras-chave: Globalização; Pluralismo Jurídico; Direito Estatal; Regulação.

1 Tradução do original em inglês por Luciana de Andrade Amoroso Remer. Revisão da tradução por Marcos Augusto Maliska. 


\begin{abstract}
Globalization is not a descriptive term to depict the contemporary realities of law; it works mainly as a regulatory conception to affirm certain regularities of social evolution to be respected by scholars, lawyers, and politicians. The reflections about law in the era of globalization do not represent law as it is, but rather prescribe which law is needed for mankind to meet the perils of our changing times. Unanimously rejecting the Hobbesian model, the pluralists depict human societies as self-organizing entities capable of producing their own autonomous regulation, independent of the will and discretion of particular individuals. The phenomena summed under the title of legal pluralism have neither historical nor social originality as such. Legal pluralism does not reveal new social laws or regularities, it does not provide new explicative schema (rather it merely changes the words in the older schema), and the challenges of globalization are only relatively new. Rather the reality referred to through these terms outlines a renewed intellectual climate which offers new axes for discourses. From this point of view, the problem of legal pluralism, and the issue of globalization are not devoid of scientific interest, and discussions on this matter can effectively contribute to the progress of social knowledge. But, in all probability, one cannot reasonably expect that from replacing terms and factual data one can gain innovative knowledge about the interrelation of law and society.

Key-words: Globalization; Legal pluralism; State Law; Regulation
\end{abstract}

\title{
1. INTRODUÇÃO
}

A noção de globalização é relativamente imprecisa, e pode ser popularmente utilizada para abarcar uma grande variedade de fenômenos modernos. Teóricos abusam das palavras-G (um termo de Willian Twining ${ }^{2}$ ) para demonstrar mudanças radicais, ou ao menos as mudanças que parecem radicais para alguns filósofos. Referências generalizadas para novas (quase-) realidades permitem aos teóricos se eximirem de uma longa e trabalhosa análise e comparação de fenômenos jurídicos do passado e do presente. Esse novo tipo de reducionismo não pretende descrever sistemas complexos por meio de um ou vários elementos predominantes, como o paradigma científico clássico o faz. Pelo contrário, é evidente que a crescente complexidade do mundo demanda uma abordagem multidimensional, na tentativa de alcançar toda a noção da realidade ${ }^{3}$.

A necessidade de uma explicação plausível dessa realidade multidimensional leva a uma junção da terminologia herdada da tradição científica clássica, e da

\footnotetext{
2 Cf. W. Twining, Globalization and legal education, Nijmegen 2011.

3 No que diz respeito à aplicação da teoria da aplicação da teoria dos sistemas, ver: C. Gopinath, Globalization:A Multidimensional System, New York 2008.
} 
metodologia inspirada pelas filosofias pós-clássicas. Mesmo nessa última parte, o paradigma clássico de conhecimento científico não deixa alternativa para a dicotomia "sujeito-objeto", e uma visão renovada do mundo remanesce cativa para a linguagem científica da modernidade ${ }^{4}$. Essa junção leva ao crescimento de concepções vulgares, que parecem dizer novas coisas nas ciências jurídicas somente acrescentando novos termos carregados de inúmeras conotações. A falta de sentido dessas reformulações generalizadas pode ser verificada em muitas abordagens não rigorosas acerca do "pluralismo jurídico global", que recentemente se tornou um dos rótulos para generalizar algumas tendências na civilização contemporânea. "Globalização", "pluralismo", "sustentabilidade" e outras palavras são colocadas juntas aqui para descrever as novas realidades do mundo em transformação de uma perspectiva totalmente nova. A jurisprudência sempre apresenta extrema vigília em torno de ideias capazes de distorcer a linguagem pelas quais os legisladores escrevem as leis para os leigos e discutem a aplicação dessas leis entre eles. A descrição do direito, como se ele fosse aplicável somente aos Estados nacionais, se tornou evidentemente obsoleta nos dias de hoje ${ }^{5}$, e as realidades referidas como "globais" precisam reconstruir o vocabulário tradicional da ciência jurídica ${ }^{6}$. Aqui se encontra a verdadeira abordagem pluralista/global do direito, mas algumas ressalvas importantes devem ser feitas. Tentaremos apresentá-las a seguir.

\section{EM BUSCA DO PLURALISMO JURÍDICO GLOBAL}

Essas palavras-G se tornaram um Klondike para campanhas de arrecadação de fundos em várias disciplinas, mas em qual medida as realidades em questão são fundamentalmente novas, que não poderiam ser descritas pelas noções e explicações anteriormente apresentadas nas ciências jurídicas? Em outras palavras, esses novos

\footnotetext{
${ }^{4}$ Sobre os problemas para descrever os fenômenos jurídicos por meio de esquemas fundamentalistas e categorias, ver: B. Melkevik, La philosophie du droit dans le tourbillon de la modernité (in Russian), in: Russian Yearbook of Legal Theory 2009, No. 2, pp. 527-545.

${ }^{5}$ Ver a magistral acusação contra a linguagem legal tradicional: P. Schlag, Formalism and Realism in Ruins (Mapping the Logics of Collapse), in: lowa Law Review 2010, No 95.

${ }^{6} W$. Krawietz, Weltrechtssystem oder Globalisierung des Rechts? Konstruktion und Rekonstruktion der modernen Welt des Rechts in kommunikations- und systemtheoretischer Perspektive, in: Rechtstheorie 39 (2008), S. 419-451; M. Schulte, Weltrecht in der Weltgesellschaft. Prolegomena zu einer Selbstbeschreibung und Fremdbeschreibung des Rechtssystems als Weltrechtssystem, ibid., S. 143 164; M. Meckel, Kulturelle Konfrontation oder kommunikative Konvergenz in der Weltgesellschaft? Kommunikation im Zeitalter der Globalisierung, in: Rechtstheorie 29 (1998), S. 425-440; J. A. Treviño, The Sociology of Law in Global Perspective, in: American Sociologist 32 (2001), pp. 5-9.
}

Revista de Direitos Fundamentais \& Democracia, Curitiba, v. 26, n. 1, p. 238-257, jan./abr. 2021. 
conceitos (no nosso caso, "globalização" e "pluralismo"7) são analiticamente necessários para descrever o direito na sociedade moderna (ou, como alguns dizem, "pós-moderna")? Esses conceitos podem ser úteis para descrever as tendências controversas no mundo contemporâneo; inclusive, nossa hipótese é que eles refletem novos modelos de pensamento jurídico e assim ganham a habilidade de servir como conceitos regulatórios. Uma de suas funções é facilitar a descrição de novas formas de controle social. Ao mesmo tempo, parece não haver razões que sustentem as demandas daqueles teóricos que clamam pela descoberta de novas verdades, os quais as descrevem com referência às palavras-G.

$\mathrm{Na}$ verdade, ao descrever o direito tal como se apresenta nas sociedades modernas, verificam-se dificuldades até mesmo no nível da atribuição de termos e noções para o conjunto de fatos que não tem qualquer explicação satisfatória na doutrina jurídica monista do Estado. Essas não são as únicas: lex mercatoria e ordens jurídicas não estatais semelhantes são conhecidas há muito tempo. Um direito contratual uniforme, tampouco as tentativas de empresas comerciais de criar uma rede internacional de institutos legais são novos - pode-se mencionar a Hansa ou os juristas romanos que criaram projetos semelhantes no campo jurídico, explorando novas ferramentas para moldar um mundo no qual pudessem gerar frutos de acordo com as regras por eles determinadas ${ }^{8}$. Como consequência, os novos fatos referidos como "pluralismo jurídico" ou "globalização", não contém nada de extraordinário ou novo. Dessa perspectiva, o próprio fato de um "mundo em transformação" não autoriza os pensadores a abandonarem as antigas noções e explicações desenhadas e imprudentemente apresentar novas ideias.

Nesse sentido, de um suposto "fim da história", o qual pressupõe que um capitalismo global e moderno, nos contornos de uma política democrática liberal, representa a última palavra da evolução socioeconômica ${ }^{9}$, pode parecer mera hipérbole desprovida de qualquer potencial explicativo. Dessa perspectiva, tende-se a afirmar que não há nada de novo sob o sol ("nil sub sole novum"), contrariando aqueles que declaram ter descoberto novas verdades no direito contemporâneo e que desejam

7 Esses dois aspectos são integrados com sucesso pelo termo 'Glokalisierung' proposto por R. Robertson, Glokalisierung: Homogenität im Raum und Zeit, in: U. Beck (ed.), Perspektiven der Weltgesellschaft, Frankfurt a. M. 1998. S. $192-220$, e desenvolvido na filosofia do direito por W. Krawietz, Glokalisierung der Rechtskommunikation? Zum Globalisierungsdiskurs in der modernen Rechts- und Gesellschaftstheorie, in: Rechtstheorie 35 (2004).

8 Cf. G. Modelski/T. Devezas/W. R. Thompson (eds.), Globalization as Evolutionary Process: Modeling Global Change, London 2008.

${ }^{9}$ F. Fukuyama, The End of History and the Last Man, New York 1992. 
atribuir novos rótulos a essas realidades. Entretanto, essa negação constituiria a outra extremidade conceitual. Céticos diriam que nosso mundo em transformação está reproduzindo antigos padrões, ao invés de criar algum fenômeno substancialmente novo, pois os processos contemporâneos de globalização são apenas versões do velho capitalismo ${ }^{10}$. Nessa medida, esse ceticismo não é construtivo; como tal, novas noções e termos não colocam em risco a ciência jurídica, desde que sejam usados corretamente e em um contexto apropriado, sem discriminação indevida contra os antigos conceitos. Na nossa opinião, é a definição de tal contexto que se apresenta como um dos principais obstáculos à exploração das mudanças jurídicas pelas lentes da filosofia ou do direito global.

A intensidade da transformação social em nosso tempo é impressionante, e as mudanças no campo jurídico são evidentes ${ }^{11}$. Reconhecendo que o direito tem se tornado muito (embora não completamente) diferente, se comparado com o direito existente na tradição ocidental até a metade do Século 20 , pode-se legitimamente argumentar em favor de um novo termo que descreva essa nova realidade jurídica. Essa realidade relativamente nova pode ser chamada "globalizada" ou qualquer outra "palavra-G", sem o surgimento de significativas discussões acerca das palavras atribuídas pelas pessoas às coisas; simplesmente porque não há critério objetivo para a veracidade desses termos. Pode-se aderir à clássica definição de Giddens que viu a globalização como a intensificação das relações mundiais, que conectam localidades distantes de tal forma que acontecimentos locais são moldados por eventos ocorridos em lugares muito distantes ${ }^{12}$; ou definir a globalização de acordo com Wallerstein, como um processo incerto de transação mundial no quadro de uma alternativa sócio econômica desconhecida; ou pode-se optar por outra definição, que seria igualmente plausível. Contudo, se a discussão perdurar não apenas na dimensão "nominalista", mas também na "realista" (a analogia com a controvérsia medieval sobre os reais institutos por detrás das palavras, parece ser sugestiva aqui), precisa-se decidir conforme a necessidade lógica de se estabelecer ligações entre os mais novos termos apresentados e os fenômenos descritos pelos conceitos mais antigos.

Desse ponto de vista, a resolução de problemas científicos intratáveis seria melhor conduzida não pela criação de uma nova linguagem (Novdroit, se utilizarmos o

\footnotetext{
${ }^{10}$ I. Wallerstein, Globalization or the Age of Transition? (A Long Term View of the Trajectory of the World System). http://fbc.binghamton.edu/iwtrajws.htm.

11 D. Held/A. McGrew, Global Transformations, Cambridge 1999.

${ }^{12}$ A. Giddens, The Consequences of Modernity, Cambridge 1990, p. 64.
}

Revista de Direitos Fundamentais \& Democracia, Curitiba, v. 26, n. 1, p. 238-257, jan./abr. 2021. 
conceito apresentado pelo Professor Melkevik ${ }^{13}$ ) mas por meio de uma crítica às tentativas de criação dessa nova linguagem (uma crítica entendida de uma perspectiva construtiva Kantiana). O principal ponto dessa crítica é diferenciar a linguagem objetiva do direito da metalinguagem que é usada para descrevê-lo. A nova narrativa em torno do direito no mundo globalizado não descreve a linguagem usada por juristas, legisladores, juízes; prefere-se moldar uma nova perspectiva mundial na qual o direito adquire novas qualidades específicas, que não possuía anteriormente ${ }^{14}$. A utilização dessa linguagem objetiva não proporciona o conceito de globalização com qualquer poder explicativo, porquanto o "vocabulário da globalização" no âmbito do direito (aqui nos abstemos de qualquer conclusão sobre economia, política, e outras esferas sociais) não proporciona as ferramentas conceituais para descrevê-lo.

Ao analisar esse vocabulário, pode-se dizer que a principal característica da globalização jurídica é uma tendência à privatização do que é juridicamente público ${ }^{15}$. Muitos autores sustentam que o centro gravitacional do direito deixou de ser um produto da vontade do Estado, para ser contratos entre indivíduos (mesmo que esses "indivíduos" sejam grandes companhias multinacionais); portanto, existem grandes desafios para o monopólio estatal instalado na manutenção e administração do direito. Isso passa de mão em mão com grande perda da soberania estatal, como consequência dos avanços do direito supranacional e transnacional. Afirma-se que a forma tradicional de soberania, por exemplo, a soberania da exclusividade jurisdicional, não mais existe na era moderna de sistemas jurídicos globalizados. Pelo contrário, a participação em estruturas plurais ou mistas (às vezes chamadas "plurilateral"16) é a forma prevalente de soberania em tempos de economia global ${ }^{17}$. Consequentemente, há o crescimento do poder dos agentes não estatais com a criação de novas fontes do

\footnotetext{
${ }^{13}$ B. Melkevik, Parlez «Novdroit»! Ou comment le politiquement correct se legitime «juridiquement» (in Russian), in: Pravovedenie 2012, No. 1, pp. 37-56. Ver também B. Melkevik, Philosophie du Droit, Quebec 2012.

14 W. Krawietz, Narrative Jurisprudenz oder Theorie der Rechtskommunikation? Überlegungen zu einer Geschichtenphänomenologie der Recht, in: Festschrift für Jan Schapp zum siebzigsten Geburtstag, Tübingen 2010, S. $311-328$.

15 R. Michaels/N. Jansen, Private Law beyond the State? Europeanization, Globalization, Privatization, in: American Journal of Comparative Law 54 (2006).

${ }^{16}$ P. Cerny, Globalization and the Changing Logic of Collective Action, in: International Organization 49 (1995), p. 446.

17 Cf. J. Jackson, Sovereignty: A New Approach to an Outdated Concept, in: American Journal of International Law 97 (2003), No 4. Sobre as implementações teóricas para a Rússia cf. M. Antonov, Theoretical Issues of Sovereignty in Russia and Russian Law, in: Review of Central and East European Law 2012, No. 1, pp. 95-113.
} 
direito. $^{18}$

Nessas discussões, o termo "globalização" equivale apenas à afirmação da tendência de crescente interconexão e interdependência entre todos os países e sociedades do mundo ${ }^{19}$. Esse é um processo cujo mecanismo é o comércio internacional e o fluxo de capital, e o direito aqui pode ser visto como destinatário dessas mudanças. Um exemplo típico é a já citada "lex mercatória", que regula o comércio internacional e não é feita por governos nacionais ou por instituições públicas de natureza internacional, mas por uma maioria de atores de direito privado ${ }^{20}$. Daí emerge um novo tipo de soft law em que o recurso à coerção é menos importante do que no direito estatal, porque esse novo tipo de direito funciona como meio de ligação estrutural dos processos sociais. ${ }^{21}$. Como exemplos desse direito não vinculativo podem ser citados, tanto ordenamentos de direito privado, quanto ICCAN, UDRP, as normas produzidas pelo corpo de apelação do WTO, regras procedimentais de arbitragem internacional, padrões de EDI/EDIFACT, e assim por diante.

Esses exemplos confirmam que as transformações econômicas (denominados de "globalização"), na verdade, tem um efeito significativo no direito; as mudanças demandadas no direito, pelas alterações econômicas da modernidade, ajudam a transformar muitos institutos jurídicos, proporcionando o crescimento de novas formas de adjudicação, modificando as funções clássicas do direito, e produzindo outras mudanças importantes na esfera jurídica (no âmbito nacional e internacional). Sob esse enfoque, a adoção de um "vocabulário da globalização" nada mais é do que a reafirmação da verdade velha e banal sobre a interconexão entre direito e economia22: considerando que as estruturas econômicas são sujeitas às mudanças da "globalização", pode-se esperar razoavelmente que a lei se sujeitaria a mudanças similares. A maior parte das discussões sobre "Direito e Globalização" levam à defesa

${ }^{18} \mathrm{~K}$. Jayasuriya, The Rule of Law in the Era of Globalization: Globalization, Law and the Transformation of Sovereignty: The Emergence of Global Regulatory Governance, in: Indiana Journal of Global Legal Studies 1999, No. 6.

${ }^{19}$ É sintomático que o Banco Mundial defina a globalização como, "the growing integration of economies and societies around the world" (The World Bank Group. Globalization. http://www1.worldbank.org/economicpolicy/globalization/ March 22, 2008).

20 C. Cutler, Private Power and Public Authority: Transnational Merchant Law in the Global Political Economy, Cambridge 2003.

21 Cf. W. Krawietz, Ausdifferenzierung des modernen Rechtssystems und normative strukturelle Kopplung - sozietal oder sozial?, in: G. Peter/R.-M. Krauße (eds.), Selbstbeobachtung der modernen Gesellschaft und die neuen Grenzen des Sozialen, Berlin 2012, pp. 73- 101.

22 O classico exemplo desse entendimento é o conceito do jurista soviético Evgeny Pashukanis, que descreveu o direito como uma paráfrase das trocas econômicas: E. Pashukanis, The General Theory of Law and Marxism, in: id., Selected Writings on Marxism and Law, ed. by P. Beirne and R. Sharlet, London/New York 1980, pp. $32-131$. 
de necessárias mudanças no direito que deveria ser produzido de acordo com as transformações econômicas apropriadas no mercado global, além de atualizar o direito para adequá-lo à nova realidade econômica globalizada. Dessa perspectiva "Direito e Globalização" poderia ser visto como mera seção de "Direito e Economia", e, especialmente desse ponto de vista, as predições dos partidários da retórica globalista/pluralista trazem ao pensamento as profecias de Karl Marx - em ambos os casos o prognóstico de "atrofiamento" do direito (ao menos, o direito tal como concebido na tradição jurídica ocidental) são baseados em certas tendências econômicas genéricas.

Até então, concordamos que essa conexão entre direito e economia é importante para a maioria dos pensadores jurídicos. No entanto, ter em mente o problema ser/dever-ser e relembrar a lâmina da guilhotina de Hume (não se pode extrair um "Dever-ser" de um "Ser") impede que um meticuloso pesquisador extrapole acriticamente os resultados obtidos de uma observação da situação econômica contemporânea na esfera jurídica. Em economia essas observações são de caráter essencialmente descritivo; inseridas no campo jurídico, elas adquirem uma conotação prescritiva: "do fato dos mercados globais emergentes, e da interconexão apresentada entre direito e economia, pode-se esperar que o direito também deveria...", e, assim, extrair implicações para o desenvolvimento, tanto do sistema jurídico doméstico, como do direito internacional ${ }^{23}$. Essa conotação prescritiva é melhor apresentada na combinação do termo "globalização" com outro rótulo em voga, "sustentabilidade"24, que prescreve "que nós reconheçamos as origens primitivas das disfunções ecológicas humanas e tomemos o controle consciente de nosso destino coletivo"25.

Refletindo sobre as origens da modalidade prescritiva que caracteriza as conclusões extraídas do "vocabulário da globalização", é muito importante não perder de vista o fato de que o direito não apenas sofreu os efeitos da globalização, mas também atuou como uma regra no processo, e esses efeitos seriam impossíveis se os

\footnotetext{
23 Um exemplo típico dessa "mudança imperceptível", tão lamentada por David Hume, pode ser encontrada nos trabalhos de David Gerber onde o autor conclui suas reflexões listando imperativos a serem seguidos pelos governos em tempos de globalização (D. Gerber, Global Competition: Law, Markets, and Globalization, Oxford 2010).

${ }^{24}$ N. A. Ashford/R. P. Hall, Technology, Globalization, and Sustainable Development: Transforming the Industrial State, Yale 2011. Nesse livro, os autores requerem uma lei sobre integração econômica, desenvolvimento industrial, direito nacional e internacional para atender aos desafios da globalização. Muito da literatura sobre direito-globalização-sustentabilidade está sobrecarregada de demandas deontológicas semelhantes.

25 W. E. Rees, Globalization and Sustainability: Conflict or Convergence?, in: Bulletin of Science, Technology and Society, August 2002 No. 22, p. 249.
} 
instrumentos jurídicos necessários já não tivessem sido apresentados (explícita ou implicitamente) pelo direito. Somente pode-se falar em mudanças e transformações no direito enquanto direito e não quando se torna algo diferente, como um conglomerado de regras sociais não diferenciáveis de tabus, superstições e tradições que são típicas das sociedades primitivas ${ }^{26}$. Ainda é o direito que autoritariamente governa o comportamento humano por meio de prescrições imperativas, sustentadas por sanções socialmente organizadas ${ }^{27}$. Resta a linguagem como objeto da regulamentação normativa. Se se admite que nada muda essa natureza do direito nas sociedades modernas, até mesmo no contexto de processos globalizados, então o uso do "vocabulário da globalização" pode ser enquadrado apenas como um tipo de política, enquanto processo deliberativo no qual sociedade e indivíduos expressam suas opiniões sobre compromissos entre direito estatal e direito livre (social, econômico) ${ }^{28}$. Desse ponto de vista, o "vocabulário da globalização" pode servir hoje como um substituto da antiga (e provavelmente desatualizada) ideia de direito natural. Lyotard ressaltou que "modernidade, em qualquer tempo em que surgir, não pode existir sem a ruptura de convicções e sem a descoberta da 'falta de realidade' da realidade, juntamente com a invenção de outras realidades" 29 . Mas a questão é se existe uma realidade "real" e se há uma única modernidade ou múltiplas modernidades ${ }^{30}$. Em último caso, nenhuma contradição performativa surge do pouco que soa como construtivismo para explicar a evolução do conhecimento científico.

É útil traçar um paralelo com as ideias do direito natural, que emergiu toda vez que a sociedade teve que lidar com problemas não resolvíveis por meio dos instrumentos de regulamentação jurídica disponíveis à época. O problema do direito

\footnotetext{
${ }^{26}$ O rótulo de "direito" também pode ser atribuído a esses regulamentos em razão da simplificação de certos modelos de pesquisa, conforme feito, e.g., por Bronislaw Malinowski. Mas a generalização desses modelos como ferramentas de explicação universal é altamente questionável, pois nada exige que um pesquisador use o mesmo vocabulário de tribos primitivas para estudos antropológicos e para exame do desenvolvimento jurídico das chamadas "nações civilizadas" (essa expressão ainda é sabiamente utilizada no direito internacional). Essas áreas podem ser naturalmente representadas como entrecruzadas (e não excludentes uma da outra), mas mesmo assim a diferença de regulação jurídica nessas áreas permanece aparente e então requer uma discriminação crítica entre os termos respectivamente aplicados para seu exame.

27 Esse entendimento do direito pode ser encontrado em, e. g.: N. S. Timasheff, An Introduction to the Sociology of Law, Transaction Publishers 1939.

28 "Em que medida a lógica do sistema de mercado deve ser abrandada, onde e em que estrutura o mercado deve 'governar'; são, em última instância, questões que, em uma sociedade moderna, devem ser deixadas para a decisão política deliberativa". (J. Habermas, Crossing globalization's valley of tears, in: New Perspectives Quarterly 17 (2000), p. 55).

29 J. F. Lyotard, The Postmodern Condition: A Report on Knowledge, Minneapolis 1984, p. 77.

30 S. E. Eisenstadt, Multiple Modernities - A Paradigma of Cultural and Social Evolution, in: ProtoSociology 24 (2007).
}

Revista de Direitos Fundamentais \& Democracia, Curitiba, v. 26, n. 1, p. 238-257, jan./abr. 2021. 
natural foca, primeiramente, na questão do alicerce axiomático do direito. Há várias versões do jus naturale que descrevem (ou preferem prescrever) diferentemente esses alicerces. Por exemplo, o posicionamento de Dworkin que enriquece significativamente a forma jus-naturalista de pensar, i.e. por meio de reflexões em torno da integridade do direito. Para ele, a integridade do direito é uma ideia regulatória, que subsidia a possibilidade de estudá-lo como um objeto independente: "Direito como integridade requer aos juízes que presumam, tanto quanto possível, que o direito é estruturado por um conjunto coerente de princípios sobre justiça, equidade e devido processo, demandando-Ihes que o apliquem aos novos casos que lhes forem apresentados, para que a situação de cada pessoa seja justa e esteja de acordo com os mesmos padrões"31. A partir de então é que a integridade do direito é resultado de nosso raciocínio coerente acerca do direito. Essa coerência, novamente, pode ser garantida pelo uso consistente de termos e noções que constituem esse raciocínio.

Portanto, em se tratando de transformações jurídica, deve-se prestar atenção não a quaisquer fatores externos (à cognição humana), mas à "lógica" interna do direito, sua continuidade argumentativa, as fontes de sua força persuasiva ${ }^{32}$. Assim como, formas do direito podem mudar drasticamente ao longo do tempo; não é possível oferecer uma diretriz segura nas reflexões sobre as mudanças na natureza da regulação jurídica ${ }^{33}$. Günther sabiamente sugere que o uso reiterado da palavra "direito", por vários grupos, permite um código universal de legalidade que, por sua vez, define um forte objeto de debate intercomunitário ${ }^{34}$. Esse debate ganha muito mais impacto do que antes, devido à mídia de massa, da Internet, e de outros meios de comunicação; a proliferação dessa comunicação sobre o direito em "debates intercomunitários" pode explicar o novo formato jurídico que emerge na atualidade (ou ao menos, novas formas de raciocínio jurídico), e pode até dar azo à nova teoria do direito comunicativo ${ }^{35}$. Ao se referir à sugestiva imagem proposta por Belley, pluralismo

${ }^{31}$ R. Dworkin, Law's Empire, Cambridge 1986, p. 243.

32 Sobre as implicações da argumentação jurídica cf. B. Frydmann, Le sens des lois. Histoire de l'interprétation et de la raison juridique, Bruylant 2005; W. Krawietz, Zum Paradigmenwechsel im Juristischen Methodenstreit, in: Rechtstheorie 10 (1979), S. 113 - 152; id., Juristische Argumentation und Argumentationstheorien auf dem Prüfstand, in: id./ Robert Alexy (eds.), Metatheorie juristischer Argumentation, Berlin 1983, S. 3-84.

33 J. Dalberg-Larsen, The Unity of Law: An Illusion? On Legal Pluralism in Theory and Practice, Berlin 2000.

${ }^{34} \mathrm{~K}$. Günther, Legal pluralism or uniform concept of law? Globalization as a problem of legal theory, 2008, http://www.helsinki.fi/nofo/NoFo5Gunther.pdf

35 Ver W. Krawietz, Legal Communication in Modern Law and Legal Systems. A MultiLevel Approach to the Theory and Philosophy of Law, in: Luc J. Wintgens (ed.), My Philosophy of Law. The Law in

Revista de Direitos Fundamentais \& Democracia, Curitiba, v. 26, n. 1, p. 238-257, jan./abr. 2021. 
e globalização são somente construções mentais alternativas para representar o mundo que nos cerca, e como esses conceitos não refletem esse mundo, servem melhor como modelos explicativos ${ }^{36}$. Ou eles são estéticas alternativas, para usar o vocabulário artístico de Pierre Schlag ${ }^{37}$.

A questão em torno das transformações jurídicas torna-se, então, uma questão sobre os novos tipos de raciocínio jurídico ou discurso jurídico, se seguirmos a terminologia de Goodrich: "Discurso jurídico é simplesmente um de tantos discursos normativos concorrentes, discursos de moralidade, religião, e costumes sociais, os quais estão intrinsecamente associados, e dos quais decorrem muitos, se não todos os argumentos justificativos. É um discurso que deveria ser idealmente lido em termos de controle - de domínio e subordinação - e de enquadramento social de relações de poder e destinados a um público mais geral do que aquele somente dos fora-da-lei e mal feitores." 38 Dessa perspectiva, o direito é um sistema de hábitos que permanece externamente e destina-se a controlar "os hábitos divergentes e tônicas diferentemente direcionadas do diálogo social" 39 , mesmo que suspeitemos das tentativas de reduzir o controle social às relações de domínio e subordinação. Desenvolvendo essa linha de pensamento, pode-se facilmente entender a globalização como uma mudança de paradigma de grupos para discursos, de Estados unitários para uma Bukowina Global - a ideia apresentada e defendida por G. Teubner. 40

Se o direito funciona traduzindo a realidade social para seus próprios termos, a fim de controlá-la, então globalização, pluralismo, sustentabilidade, e outras palavras podem ser meramente concebidas apenas como sinais que indicam a nova modalidade de controle social na qual os agentes tradicionais (Estados, corporações, etc.) são substituídos por outros, onde fontes tradicionais do direito cedem a outras. Como resultado, não é o direito (como um tipo especial de discurso social) que muda; mudanças podem ser verificadas no nível da cultura geral de pensamento, onde novos

Philosophical Perspectives, Dordrecht/Boston 1999, pp. 69-120.

$365 \mathrm{~J}$. G. Belley, Le droit comme terra incognita: conquérir et construire le pluralisme juridique, Canadian Journal of Law Society 12 (1997), pp. 1-15.

${ }^{37}$ P. Schlag, The Aesthetics of American Law, in: Harvard Law Review 115 (2002).

38 P. Goodrich, Legal Discourse: Studies in Linguistics, Rhetoric, and Legal Analysis, New York 1987, p. 20.

39 lbid., p. 188.

40 G. Teubner, Global Bukowina: Legal Pluralism in the World Society, in: id. (ed.), Global Law Without a State, Dartmouth 1997, pp. 3-28. Essa abordagem é baseada na teoria sistêmica de Teubner, na qual o direito não é criado pelo Estado, mas surge espontaneamente como autocriação. Com essa teoria Teubner argumenta que um centro de criação jurídica deve ser buscado não no Estado, mas nos atores não estatais periféricos. 
termos são apresentados para demonstrar o eterno problema de coordenação do social e do individual ${ }^{41}$. Esse problema (totalidade vs. personalidade; social vs. Individual, Gesellschaft vs. Gemeinschaft ${ }^{42}$ ) não preocupa apenas os filósofos jurídicos contemporâneos. Esse paradigma pode ser descrito em termos de significados sociais e expectativas aplicadas a toda sociedade, e não apenas à modernidade da civilização ocidental ${ }^{43}$. Em outras palavras, mas essencialmente na mesma direção, os debates sobre esses princípios bivalentes levaram as gerações anteriores de teóricos do direito a questionarem a pluralidade jurídica e os atores de criação jurídica supranacionais as questões atualmente discutidas em termos de globalização. Tentativas de resolver essas questões nas ciências jurídicas por meio de um paradigma científico nãoclássico pode ser datado tão cedo quanto o início do século XX.44

Aqui é importante se afastar do entendimento da "globalização" como uma força objetiva que domina a realidade social (como se fosse algo como "força de produção" na filosofia social Marxista), como um fator unilateral que determina a criação legislativa e o processo de imposição do direito. Os efeitos da globalização acima descritos podem ser melhor vistos como resultado da interação entre diferentes institutos, estruturas e níveis do direito.Uma análise do impacto, que a doutrina jurídica constantemente renovada, exercita na mudança das instituições jurídicas, e dos impactos das discussões da globalização política e filosófica, nas mudanças na doutrina jurídica, se tornam terreno fértil para a reavaliação do constante processo de transformação no direito (que não necessariamente prova qualquer transformação do

\footnotetext{
41 Cf. G. Gurvitch, L'idée du droit social, Paris 1932. Sobre possíveis aplicações para os problemas contemporâneos do direito da sociologia jurídica de Gurvitch cf. G. Riechers, Die Normen- und Sozialtheorie des Rechts bei und nach Georges Gurvitch, Berlin 2003. Essa característica da globalização tem sido recente e novamente ressaltada por Koskenniemi (M. Koskenniemi, Global legal pluralism: multiple regimes and multiple modes of thought, 2005, http://www.helsin ki.fi/eci/Publications/MKPluralism-Harvard-05d\%5B1 \%5D.pdf).

42 Ver, nesse último ponto, W. Krawietz, Gemeinschaft und Gesellschaft. Das Tönnies'sche Handlungsund Forschungsparadigma in neueren Rechtstheorien, in: Rechtstheorie 35 (2004), S. 579-652.

${ }^{43}$ A. Gromitsaris, Symbolische und soziale Generalisierung von Erwartungen als Strukturelemente gesellschaftlichen Sinns, in: Werner Krawietz/Michael Welker (eds.), Kritik der Theorie sozialer Systeme. Auseinandersetzungen mit Luhmanns Hauptwerk, Frankfurt a. M. 1992, S. 133 -146; M. van Hoecke, Western and Non-Western Legal Cultures, in: Rechtstheorie 33 (2002), S. 197 -217.

${ }^{44}$ Cf. A. Polyakov/M. Antonov, Leon Petrazycki's Legal Theory and Contemporary Problems of Law, in: B. Melkevik (ed.), Se ergue: Hommages á Chaba Varga, Budapest 2012, pp. 371-81. Em que pesem as tentativas de encontrar o "verdadeiro" pluralismo jurídico somente na concepção da globalização, então excluindo Gurvitch e outros "clássicos" da lista de pluralistas (e. g. M. Corsale, Legal pluralism and the corporatist model in the welfare state, in: Ratio Juris 7 (1994), pp. 95 -103). Ao contrário, ao ler Santos que pluralismo jurídico é "um estado psicológico do indivíduo sujeito a mais de um conjunto de normas ou como uma descrição de um estado dinâmico de obrigações" (B. Santos, Toward a New Legal Common Sense: Law, Globalization and Emancipation, 2nd ed., Cambridge 2002), pode-se perceber uma notável similaridade com as ideias de Petrazycki, que haviam sido apresentadas um século antes.
}

Revista de Direitos Fundamentais \& Democracia, Curitiba, v. 26, n. 1, p. 238-257, jan./abr. 2021. 
direito). Desse ponto de vantagem, discutir globalização não é um objetivo em si, mas em certa medida um caminho para reafirmar, reformatar antigos conceitos jurídicos no que diz respeito às novas realidades sociais e culturais.

O problema da globalização é, portanto, equivalente ao uso do termo "globalização" no discurso jurídico. Defensores de estudos jurídicos fundamentais e a filosofia jurídica pós-moderna, que demandam "incredulidade para meta-narrativas" 45 podem discordar que não importa quais palavras são usadas para distinguir o poder factual dos governos. Todavia, conforme anteriormente verificado, não há a necessidade lógica de vincular o controle social às relações de subordinação e dominação e de igualar o controle social ao direito. Se se der um passo para o terreno inseguro de desconstrução de ferramentas de domínio cultural ${ }^{46}$, inclusive a linguagem, arrisca-se perder o principal elemento do conhecimento jurídico ${ }^{47}$. Como Gunther Teubner e Peter Korth enfatizam, se tudo se tornar direito, o direito perde sua força analítica (e também normativa) ${ }^{48}$. Dificilmente se pode esperar, encontrar uma nova concepção científica do direito, que pretenda fundir o discurso jurídico com outros tipos de discurso na sociedade e, assim, chegar a uma inferência meta-filosófica sobre a interconexão de tudo neste mundo.

À primeira vista, parece que a discussão da globalização do direito em termos de cultura jurídica oferece diversas desvantagens. Primeiramente, "cultura jurídica" como uma categoria filosófica poderia servir como base para uma análise axiomática do direito. De acordo com Roger Cotterrell, cultura jurídica pode ser definida como algo que "controla o ritmo da produção de demandas trazidas ao sistema jurídico para soluções especificamente jurídicas de problemas ou para proteção de interesses. E, por mecanismos mais obscuros e complexos, a cultura jurídica parece também determinar as respostas dos sistemas jurídicos, em parte por meio da operação da cultura jurídica interna, moldando as estruturas jurídicas, e, em parte, por meio de pressões "externas", refletindo distribuições sociais de poder e influência, que igualmente afetam as respostas do sistema"49. Dessa perspectiva, os problemas

\footnotetext{
45 J. F. Lyotard, The Postmodern Condition: A Report on Knowledge, Minneapolis 1984, p. XXIV.

46 P. Bourdieu, Pascalian Meditations, Stanford 2000.

47 Os perigos vinculados à análise do direito através das lentes de uma perspectiva cultural, e os limites dessa perspectiva tem sido constantemente discutidos. Cf. W. Krawietz/G. Riechers/K.Veddeler (eds.), Konvergenz oder Konfrontation? Transformation kultureller Identität in den Rechtssystemen an der Schwelle zum 21. Jahrhundert, Berlin 1999.

$48 \mathrm{G}$. Teubner/P. Korth, Two kinds of legal pluralism: collision of transnational regimes in the double fragmentation of world society, 2009, http://ssrn.com/abstract=1416041.

49 R. Cotterrell, The Concept of Legal Culture, in: D. Nelken (ed.), Comparing Legal Cultures, Dartmouth
} 
examinados com relação às palavras-G, parecem inicialmente estar conectados com as mudanças na cultura jurídica e, provavelmente, com algumas sérias transformações nessa cultura. Mas como tal, essas mudanças não afetam a natureza e as principais modalidades da regulamentação normativa na sociedade. Dizer que a cultura determina alterações no direito (ou na sociedade, ou em qualquer coisa do mundo humano) seria uma banalidade sem qualquer força explicativa. Assim, uma análise mais detalhada precisa estar focada em alguns elementos (selecionados a critério da pesquisa) particulares da cultura jurídica, mesmo que os elementos fossem extremamente amplos (assim como o raciocínio jurídico ou a argumentação jurídica). Um instrumento específico da cultura jurídica é o meio como o direito positivo é integrado à realidade social - o problema em discussão sob o título do pluralismo jurídico.

Se se tornar a atenção ao pluralismo jurídico, esse permanente complemento de "direito e globalização", pode-se ver a continuidade do problema pluralista no direito desde Aristóteles e Grotius. Atualmente, o crescimento do direito não estatal, adjudicação alheia às cortes oficiais, códigos e regras cooperativos e afins são normalmente discutidos sob o título de pluralismo jurídico. Ao contrário do termo globalização, o pluralismo jurídico não apresenta qualquer clamor por originalidade e exclusividade para as sociedades contemporâneas ${ }^{50}$. Por outro lado, "globalização" é um termo puramente descritivo, é relativamente novo (ainda que se trace esse termo desde os Estoicos e sua ideia de Estado cosmopolita). O termo "pluralismo jurídico" possui uma longa história e uma doutrina profundamente elaborada por trás dele. Uma vez que a permutabilidade dos termos "pluralismo jurídico" e "globalização do direito" (e os fenômenos que estariam por trás desses termos) é aceita, pode-se iniciar uma nova discussão substancial sobre as novas realidades jurídicas ${ }^{51}$. Entretanto, como Ralf Michaels acertadamente aponta, na literatura contemporânea sobre "pluralismo jurídico somado à globalização" (ou "pluralismo jurídico global") nem o pluralismo jurídico,

1997, p. 19.

50 É possível distinguir dois ou até mais conceitos de pluralismo jurídico, e. g. classico e novo (S. Merry, Legal pluralism, in: Law and Society Review 22 (1988), pp. 869 - 896), às vezes uma terceira perspectiva de pluralismo jurídico surge - que ele é conectado com os problemas da globalização (M. Hertogh, What is non-state law? Mapping the other hemisphere of the legal World, in: J. van Schooten/J. Verschuuren (eds.), International Governance and Law: State Regulation and Non-State Law, Cheltenham 2008).

51 Cf. uma excelente visão geral dessas discussões: R. Michaels, Global Legal Pluralism, in: Annual Review of Law and Social Science 5 (2009). 
tampouco o pluralismo normativo geral, em contrapartida, são tão discutidos ${ }^{52}$. O termo "pluralismo jurídico" é normalmente associado com a ideia de que o Estado tem o monopólio legislativo e que juntamente com o Estado de direito existem fontes alternativas do direito na sociedade ${ }^{53}$. Nas palavras de Franz Benda-Beckmann, pluralismo jurídico significa "a possibilidade teórica de mais de um ordenamento jurídico inserido em um espaço sócio-político, baseado nas diferentes fontes de verdadeira validação e manutenção pelas formas de organização que não o Estado"54. Conforme visto anteriormente, direito não estatal não é uma característica exclusiva do direito moderno, já era conhecido na Europa Medieval, em outras partes do mundo em diferentes épocas ${ }^{55}$. Então, a distinção das características do pluralismo jurídico será buscada em outros lugares.

Muitos desafios do direito, que são associados à globalização, assemelham-se às particularidades do ordenamento jurídico não estatal estudado pelos pluralistas jurídicos ${ }^{56}$. Juntamente com esses desafios há a coexistência do Estado de direito e direito social (nas palavras de Georges Gurvitch ${ }^{57}$ ), e a ausência de uma hierarquia única de leis que ajudariam a decidir sobre a superioridade de ordenamentos jurídicos concorrentes. Esses e outros aspectos do pluralismo jurídico atualmente emergem também em um nível global, e são reiterados em discussões sobre a globalização do direito. A questão nuclear para esse conceito, recentemente emergente de pluralismo jurídico global, passa a ser se ele constitui uma mera continuação do pluralismo jurídico tradicional, conhecido desde a antiguidade, da já conhecida discussão sobre fontes primárias e secundárias do direito ${ }^{58}$, ou são debates contemporâneos capazes

52 Ibid., p. 243.

53 J. Griffiths, What is Legal Pluralism?, in: Journal of Legal Pluralism and Unofficial Law, 24 (1986). Outra aproximação foi postular novas realidades que podem ser caracterizadas por sua porosidade ou interlegalidade, significando a unidade inseparável de ordens jurídicas (B. S. Santos, Towards a New Common Sense: Law, Science and Politics in the Paradigmatic Transition, London 1995, pp. $117 \mathrm{ff})$. Dessa perspectiva, um verdadeiro pluralismo jurídico somente aparece como conceito chave em uma visão pós-moderna do direito caracterizado pela interlegalidade.

${ }^{54}$ Benda-Beckman F., von. Who's Afraid of Legal Pluralism?, in. Journal of Legal Pluralism and Unofficial Law. 2002. No 47. p. 275. Cf. uma bem sucedida crítica do das concepções estado-centristas do pluralismo jurídico: I. Shahar, State, Society and the Relation between Them: Implication for the Study of Legal Pluralism, p. 436.

55 D. Goldman, Globalization and the Western Legal Tradition: Recurring Patterns of Law and Authority, Cambridge/New York 2007. Cf. também B. Tamanaha, Understanding legal pluralism: past to present, local to global, in: Sydney Law Review 30 (2008), pp. $375 \mathrm{ff}$.

56 Sobre os limites da abordagem pluralista do exame do direito não-estatal cf.: R. Michaels, The reState-ment of non-state law: the state, choice of law, and the challenge from global legal pluralism, in: Wayne Law Review 51 (2005).

${ }^{57}$ G. Gurvitch, Sociology of Law, New York 1942.

58 W. Krawietz, Moderne Rechtstheorie als Theorie primärer und sekundärer sozialer Systeme, in: Gerhard Preyer (ed.), Neuer Mensch und kollektive Identität in der Kommunikationsgesellschaft,

Revista de Direitos Fundamentais \& Democracia, Curitiba, v. 26, n. 1, p. 238-257, jan./abr. 2021. 
de produzir novos métodos para explicar a natureza e a realidade do direito de forma diferente.

O pluralismo é inerente à realidade social do direito, e é por isso que o pluralismo jurídico parece estar acima de qualquer suspeita para muitos pesquisadores. O direito pode ser entendido como um instrumento de coerção social, sua função ser a de levar o povo a cumprir certos atos. ${ }^{59}$ Aqui catalogados como "direito" podem ser considerados diferentes mecanismos normativos, e as muitas tentativas de diferenciá-los poderia ser suspeita de subjetivismo. Essa conclusão, feita por John Griffiths, é obviamente da perspectiva apresentada. Se se seguir Bronislaw Malinowski e se aceitar o fundamento básico do pluralismo - de que o direito abarca todos os mecanismos de controle social - então o direito está em tudo onde se encontra coerção social. Essa proposição leva inevitavelmente à negação da tese de que Estado de direito é o único direito. ${ }^{60}$ Por outro lado, considerando que os mecanismos de controle social são interligados e formam campos semiautônomos de interação social ${ }^{61}$, a especificidade da lei não pode mais ser sustentada. Dessa forma, seguindo Griffiths, é necessário abandonar até mesmo a ideia de separar o direito da moral, uma vez que o verdadeiro pluralismo jurídico não pode tolerar um único sistema normativo de regulação social. ${ }^{62}$ Deve haver muitas ordens normativas concorrentes que levem o povo a cumprir com as regras estabelecidas por essas ordens e, assim, o pluralismo jurídico será um outro nome para pluralismo normativo intrínseco à sociedade. ${ }^{63} \mathrm{E}$ pode não haver uma linha marcante entre ordens normativas.

Inúmeras objeções têm surgido contra essa descrição simplificada da realidade jurídica que implica na redução do direito oficial ao direito estatal. Essa descrição considera o direito do Estado como algo necessariamente coerente e integrado, embora nem sempre seja o caso. Até mesmo o direito estatal pode ser percebido em termos de policentrismo ${ }^{64}$, deixando um enorme campo para o "direito oficial", o qual

\footnotetext{
Wiesbaden 2009, S. $249-271$.

59 Ver observações importantes: W. Krawietz, Sind Zwang und Anerkennung Strukturelemente der Rechtsnorm?, in: Ota Weinberger/Werner Krawietz (eds.), Reine Rechtslehre im Spiegel ihrer Fortsetzer und Kritiker, Wien/New York 1988, S. 315-369.

$60 \mathrm{~J}$. Griffiths, What is Legal Pluralism?, p. 5.

61 S. F. Moore, Law and Social Change: The Semi-Autonomous Field as an Appropriate Subject of Study, in: Law and Society Review 7 (1973), pp. 719-746.

62 Cf. A.Griffiths, Legal Pluralism, in: R. Banakar/M. Travers (eds.), An Introduction to Law and Social Theory, Oxford 2002, pp. 289 -310; id., The idea of sociology of law and its relation to law and to sociology, in: Current Legal Issues 8 (2005), No. 8.

${ }^{63}$ W. Twining, Globalization and Legal Theory 2000.

${ }^{64} \mathrm{H}$. Petersen/H. Zahle (eds.), Legal Policentricity: Consequence of Pluralism in Law, Aldershot 1995.
} 
normalmente incorpora ordens legais de companhias transnacionais, escritórios de advocacia, clubes, igrejas, e entes políticos ${ }^{65}$. Um exemplo persuasivo pode ser visto na história soviética, onde o Estado e o Partido Comunista dominante da União Soviética (cujo efeito compulsivo real superou a força normativa das leis endossadas pelo governo oficial da URSS) não foram incluídos no ordenamento jurídico estatal e ficaram de fora da hierarquia de "outros atos normativos de força obrigatória" (assim como os atos da união do comércio soviético, de todas as uniões da Liga Jovem Comunista Leninista (Komsomol) e instituições análogas do sistema soviético). Conforme verificado muitas vezes na literatura pluralista, o limite entre o ordenamento jurídico estatal, o oficial, e outras formas, é vago e nem sempre permite uma clara distinção. 66

Até agora, seguimos uma linha geral de argumentação do pluralismo jurídico, mesmo que tenha se revelado totalmente problemático especificar o que é o direito genuinamente "social", puramente "não oficial", e como contrastá-lo com o direito estatal. Se o direito estatal também pode ser descrito em termos de uma abordagem pluralista, é preferível levar água ao moinho do pluralismo jurídico. Contudo, estabelecer que o direito ultrapassa a vontade do Estado e as formas escolhidas para essa vontade, em termos jurídicos, nada prova sobre a oposição ontológica do direito oficial e social. Em outras palavras, ao concordar que as normas criadas (e igualmente reconhecidas, incorporadas, deferidas, delegadas ${ }^{67}$ ) pelo Estado não exaurem todo o conjunto jurídico, vamos então necessariamente nos juntar à tese da pluralidade do direito? Não há argumentos persuasivos para dar uma resposta positiva para essa questão. Especialmente duvidosas são as afirmações de que os conflitos entre o direito estatal e o direito não estatal (leis transnacionais, étnicas, religiosas, direitos humanos) devem ser resolvidos combinando elementos de ambas as ordens jurídicas para se chegar a um direito intermediário ${ }^{68}$. Dessa perspectiva deve-se estar atento para a manutenção do distanciamento entre os aspectos terminológicos e ontológicos do problema69. É possível usar o termo "direito" para identificar diferentes mecanismos de

65 P. Berman, Global legal pluralism, in: Southern California Law Review 80 (2007) pp. 1155-1237.

66 I. Shahar, State, Society and the Relation Between Them: Implication for the Study of Legal Pluralism, in: Theoretical Inquiries in Law 2 (2008), pp. $417-441$, esp. pp. $428-430$.

67 Para se referir aos fenômenos englobados pela "versão fraca" de pluralismo jurídico criticado por J. Griffiths.

$68 \mathrm{G}$. Teubner/P. Korth, Two kinds of legal pluralism: collision of transnational regimes in the double fragmentation of world society, 2009, http://ssrn.com/abstract=1416041.

69 Ver B. Tamanaha, The Folly of the 'Social Scientific' Concept of Legal Pluralism, in: Journal of Law and Society 20 (1993), pp. 192-217; id. A Non-Essentialist Version of Legal Pluralism, in: Journal of Law and 
controle social, para agrupar aquelas realidades que já foram descritas em termos de "direitos do criminoso", "direitos das crianças"70 sob este título. O uso do termo não prova qualquer similaridade factual entre as funções exercidas por sistemas normativos (para usar "sistema normativo" no sentido concebido por Carlos Alchourron e Eugenio Bulygin ${ }^{71}$ ) de normas oficiais (estatais) e não-oficiais (não-estatais). Nenhum provou equivalência normativa desses sistemas ${ }^{72}$. Indubitavelmente, se pode aceitar que o direito não existe em uma forma "pura" estatal, que a legislação e a aplicação do direito são sustentadas por vários processos sociais, nos quais o Estado pode exercer um papel menor, ou não exercer qualquer papel. Ao mesmo tempo em que se pode manter intacta a distinção analítica entre direito e outros reguladores sociais, pode-se usar um outro esquema explicativo, que não implique em uma estrutura hierárquica da ordem jurídica global, tampouco em uma multiplicidade de ordens normativas autorregulatórias, mas em uma estrutura acoplada aos ordenamentos jurídicos mutualmente interligados ${ }^{73}$.

\section{CONCLUSÃO}

Resumindo a proposta principal de discussão sobre globalização, pluralismo jurídico e a realidade contemporânea do direito, diversas tendências comuns podem ser identificadas. Globalização não é um termo descritivo para retratar a realidade contemporânea do direito; ela funciona principalmente como uma concepção regulatória para reforçar certas regularidades da evolução social para que sejam respeitadas por estudiosos, juristas e políticos. As conclusões sobre a sólida imposição do direito positivo variam em um grau similar à discussão em torno do direito natural nos séculos XVII e XVIII. Todavia a conotação dessas imposições é facialmente

Society 27 (2000) pp. 296 -321. Teubner desenha argumentos semelhantes para se opor ao ingênuo realismo do pluralismo jurídico (G. Teubner, Two Faces of Janus: Rethinking Legal Pluralism, in: Cardozo Law Review 13 (1992), pp. 1443 -1462). Ver também M. Schulte, Recht, Staat und Gesellschaft rechtsrealistisch betrachtet, in: A. Aarnio et al. (eds.), Rechtsnorm und Rechtswirklichkeit, Berlin 1993, pp. 317-332.

70 L. Petraz ycki, Law and Morality, New Brunswick (NJ) 2011.

710 C. E. Alchourron/E. Bulygin, Normative Systems, New York 1971.

72 Cf. B. Tamanaha, The Folly of the 'Social Scientific' Concept of Legal Pluralism, p. 192. Além disso, é possível indicar que o direito estatal pode se abster do monopólio da esfera legal, mas ainda assim pode exercer uma importante função de integração dessa esfera em mais de conjunto mais ou menos coerente (S. Roberts, Against Legal Pluralism, in: Journal of Legal Pluralism 42 (1998), pp. 95 ff.).

${ }^{73}$ W. Krawietz, Moderne Rechtstheorie als Theorie primärer und sekundärer sozialer Systeme, in: Gerhard Preyer (ed.), Neuer Mensch und kollektive Identität in der Kommunikationsgesellschaft, Wiesbaden 2009, pp. 249-271. 
observável nas persistentes tendências de conectar globalização com certos processos na sociedade (particularmente, com as econômicas), que têm sido vistos como socialmente desejáveis.

Nesse ponto, as discussões sobre globalização, de certa forma, lembram a busca por ideais sociais na filosofia jurídica russa em meados dos séculos XIX e XX (toute porportion gardée!), quando muita tinta foi gasta para descrever "objetivamente" a realidade social, e dessa descrição "objetiva" concluir em favor de certos ideais de desenvolvimento suplementar da civilização. Essa "objetivação" dos modelos explicativos, por meio da conexão entre eles e as leis e regularidades supostamente encontradas na evolução social, ajudaram Marxistas, anarquistas, liberais e outros representantes das ciências sociais a sustentarem seus esquemas ideológicos no final do Século XIX. As incertezas desses dias passados lembram a ansiedade global, quando o mundo, após a queda do sistema bipolar, passou a procurar por novas estabilidades.

Os reflexos jurídicos em tempos de globalização, que foram caracterizados acima de forma generalizada, não representam o direito como ele é, mas descrevem o direito necessário para que a humanidade encontre os perigos dos tempos de transição. Essas reflexões remetem ao principal problema ideológico (de acordo com Mannheim ${ }^{74}$ ) da correlação entre individualismo e totalitarismo social, que foi tão presente nos trabalhos de Marx, Durkheim, Weber, Tarde e que estão ainda presentes nos inúmeros escritos do pluralismo jurídico. Rejeitando por unanimidade o modelo Hobbesiano, os pluralistas apresentam as sociedades humanas como entidades autoorganizadas capazes de produzir suas próprias normas autônomas, independentes da vontade e da discricionariedade dos indivíduos particulares ${ }^{75}$. Naturalmente, a questão em torno do papel do libre arbitre dos indivíduos, no desenvolvimento social, se torna uma das preocupações centrais da filosofia ${ }^{76}$. A gama de soluções possíveis é muito

\footnotetext{
74 O conceito de "ideologia" deve ser entendido aqui nos termos da filosofia social de Mannheim, como uma "perspectiva inevitavelmente associada a um dado contexto histórico e social" que se sustenta no problema hermenêutico da relação entre o todo e as partes (K. Mannheim, Ideology and Utopia. An Introduction to the Sociology of Knowledge, London 1960, p. 111).

75 Naturalmente, o entendimento dual da realidade social, como existência independente insinuada de sujeito coletivo e sujeito individual também é possível fora da filosofia do pluralismo jurídico. Ver W. Krawietz, Beyond Methodological and Theoretical Individualism Are There Collective Actors or Collective Subjects in Modern Legal Systems?, in: Ewa Czerwinska-Schupp (ed.), Values and Norms in the Age of Globalization, Frankfurt a. M. 2007, pp. 385-396. Sintomaticamente, Krawietz chega a resultado semelhante que os pluralistas para descrever a realidade social do direito.

$76 \mathrm{O}$ debate entre Habermas e Rawls pode ser citado aqui como um dos melhores exemplos (cf. B. Melkevik, Rawls ou Habermas. Une question de philosophie du droit, Quebec 2002).
} 
extensa, do anarquismo social de Friedrich Hayek à harmonia universal dos sistemas sociais dos escritos de Niklas Luhmann ${ }^{77}$. De qualquer maneira, encontrar uma resposta para essa questão requer amplos esforços filosóficos.

Os fenômenos resumidos sob o título de pluralismo jurídico não têm originalidade histórica ou social. Pluralismo jurídico não revela novos direitos sociais ou regularidades, não provê um esquema explicativo novo (em vez disso, apenas muda as palavras do esquema antigo), e os desafios da globalização são apenas relativamente novos. Ao menos a realidade referida a esses termos esboça um clima intelectual renovado que oferece novos eixos aos discursos. Desse ponto de vista, o problema do pluralismo jurídico e a questão da globalização, não são desprovidos de interesse científico, e discussões sobre o tema podem efetivamente contribuir para o progresso do conhecimento social. Mas, de todas as possibilidades, não é razoável esperar que da substituição dos termos e dados factuais, se possa obter um conhecimento inovador sobre a inter-relação entre direito e sociedade. Um campo mais fértil para cultivar esse conhecimento é aquele de reflexões sobre as questões fundamentais da filosofia social e da jurisprudência sociológica. ${ }^{78}$

Recebido em 26/03/2021

Aprovado em 27/04/2021

Received in 26/03/2021

Approved in 27/04/2021

\footnotetext{
77 N. Luhmann, Interesse und Interessenjurisprudenz im Spannungsfeld von Gesetzgebung und Rechtsprechung, in: Zeitschrift für neuere Rechtsgeschichte 12 (1990), pp. 1-13; id., Ausdifferenzierung des Rechts. Beiträge zur Rechtssoziologie und Rechtstheorie, Frankfurt a. M. 1980; id., Die soziologische Beobachtung des Rechts, Frankfurt a. M., 1986; id., Das Recht der Gesellschaft, Frankfurt a. M. 1993. Ver também importantes considerações: W. Krawietz, Neue Sequenzierung der Theoriebildung und Kritik der allgemeinen Theorie sozialer Systeme, in: W. Krawietz/M. Welker (eds.), Kritik der Theorie sozialer Systeme. Auseinandersetzungen mit Luhmanns Hauptwerk, Frankfurt a. M. 1992, pp. $14-42$.

78 Ver W. Krawietz, The Contemporary Law and the System of Law in the Perspective of the Communicative Theory, in: Russian Yearbook of Legal Theory 2011, N. 4, pp. 168-179 (Em russo).
}

Revista de Direitos Fundamentais \& Democracia, Curitiba, v. 26, n. 1, p. 238-257, jan./abr. 2021. 